\title{
Short communication: Identification and differentiation of bifidobacteria obtained from Ukraine
}

\author{
L. L. Tmanova, A. Onyenwoke, and R. F. Roberts ${ }^{1}$ \\ Food Science Department, The Pennsylvania State University, University Park 16802
}

\begin{abstract}
Ten freeze-dried bifidobacterial strains used as probiotics in Ukrainian dairy foods, identified by the supplier as Bifidobacterium adolescentis (2), Bifidobacterium bifidum (2), Bifidobacterium longum (4), Bifidobacterium animalis (1), and Bifidobacterium infantis (1), were characterized. Following rehydration and anaerobic growth on de Man, Rogosa, and Sharpe-cysteine medium at $37^{\circ} \mathrm{C}$ for $72 \mathrm{~h}$, single-colony isolates were picked and evaluated using PCR primers specific for the Bifidobacterium genus, for the supplier-identified species, and for $B$. animalis ssp. lactis. All isolates were identified as members of the genus Bifidobacterium; however, species-specific PCR revealed all 10 isolates were actually strains of $B$. animalis ssp. lactis. Further evaluation using pulsed-field gel electrophoresis was only able to separate a single strain (RT 09) from the other 9 strains evaluated. Application of genome-wide allelic profiling to the Ukrainian bifidobacterial strains revealed 4 distinct groups. Interestingly, $6(60 \%)$ of the isolates fell into the same cluster as that containing the common commercial probiotic strain BB-12. Two of the strains (RT 02 and RT 09) were found to be in the same group as ATCC 27536 and one strain (RT 08) was in the same group as the RB 7239 (a previously evaluated commercial strain). One strain, RT 04, was placed on a unique branch. These results highlight the importance of employing routine typing of bifidobacterial isolates, demonstrate the utility of single nucleotide polymorphism/insertion-deletion polymorphism-based allelic typing in $B$. animalis ssp. lactis strain differentiation and further point to the limited genetic variability of $B$. animalis ssp. lactis strains and the worldwide distribution of a small number of commercial strains.
\end{abstract}

Key words: polymerase chain reaction, pulsed-field gel electrophoresis, single nucleotide polymorphism, Bifidobacterium animalis ssp. lactis

Received April 13, 2011.

Accepted August 10, 2011.

${ }^{1}$ Corresponding author: rfr3@psu.edu

\section{Short Communication}

Probiotic bacteria are used extensively in dairy products in Ukraine (Kvasnikov, 1992; Bondarenko et al., 1998; Kovalenko; 2002). Many of these organisms are bifidobacteria that are added to fermented milk products for their putative health-promoting properties (Grigorov et al., 2002; Ott and Chagarovskiy, 2002). Because the Ukrainian strains analyzed in this work have been used for many years and were not widely available in the West, they could represent a source of new strains with potentially novel characteristics.

Given the lack of information on bifidobacterial isolates used in Ukraine, the objective of the present research was to identify 10 bifidobacterial cultures used in Ukraine as probiotics in fermented dairy products to the genus and species levels and to differentiate the cultures at the strain level using molecular methods.

The bifidobacterial strains evaluated in this work were obtained from a commercial starter culture supplier in Ukraine as freeze-dried stock cultures. Each strain was assigned a unique laboratory number beginning with RT when it was received in the Roberts research laboratory (The Pennsylvania State University, University Park). The Ukrainian strains studied in the work are available from the corresponding author for non-commercial purposes. Reference strains used in this work were obtained from the American Type Culture Collection (ATCC, Manassas, VA) and Deutsche Sammlung von Milkorganismen und Zellkulturen $\mathrm{GmbH}$ (DSMZ, German Collection of Microorganisms and Cell Cultures, Braunschweig, Germany; Table 1).

All bifidobacterial strains were cultured in liver lactose broth (LLB; Lapierre et al., 1992) or de Man, Rogosa, and Sharpe (MRS) broth (Becton, Dickinson and Co., Sparks, MD) with $0.05 \%$ L-cysteine hydrochloride (Sigma, St. Louis, MO). When solidified media were required, $15 \mathrm{~g} / \mathrm{L}$ of agar was added to LLB and MRS broth.

Duplicate sets of the 10 bifidobacterial isolates were obtained from the culture supplier as lyophilized preparations. The 2 preparations were stored at $-70^{\circ} \mathrm{C}$ and analyzed separately. A vial containing an RT isolate was aseptically opened and a sample of the dried pow- 
Table 1. Microorganisms used in this research

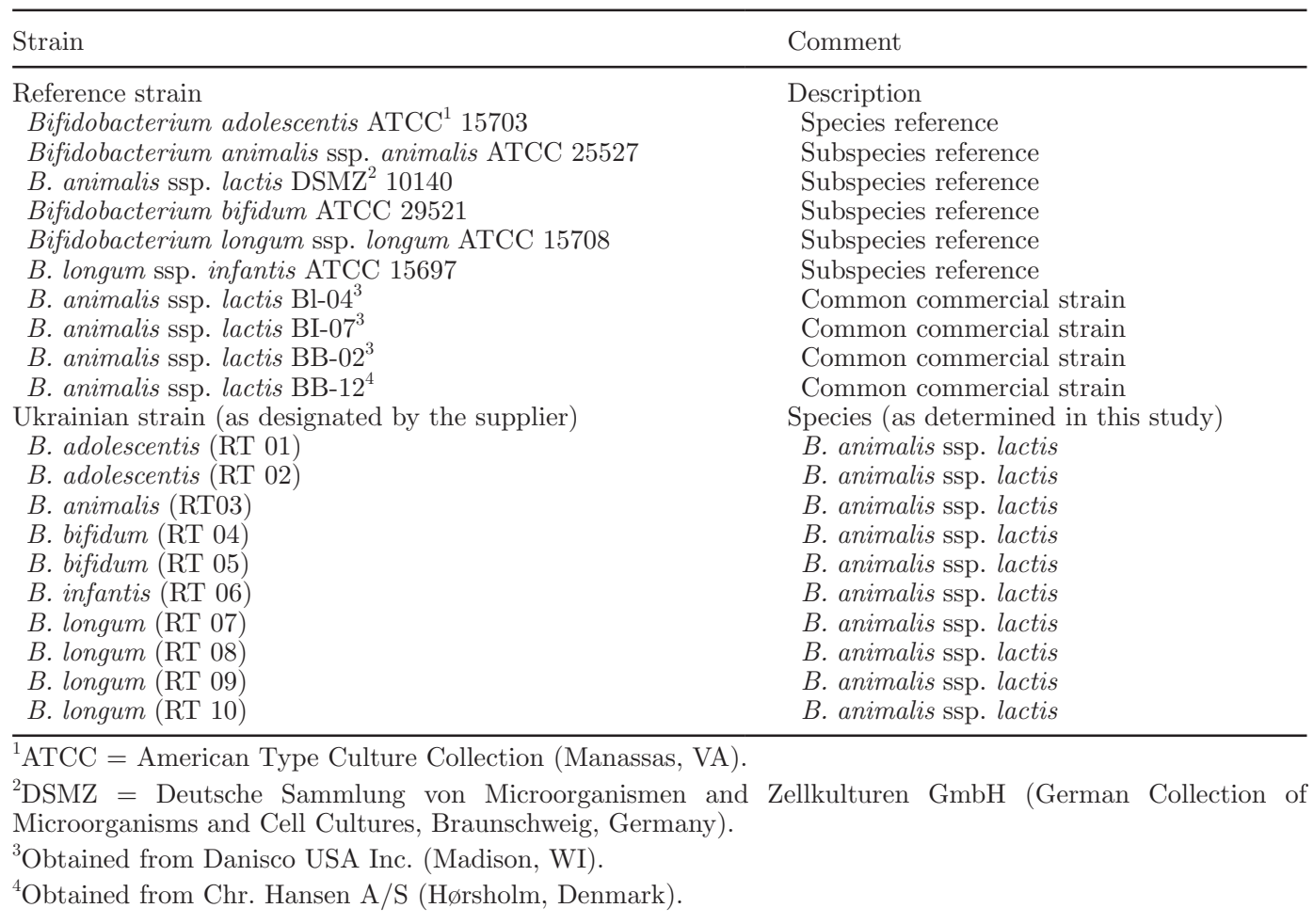

der was obtained by touching with a sterile inoculating loop moistened with LLB. These samples were transferred into sterile PCR tubes and stored frozen at $-70^{\circ} \mathrm{C}$ before analysis by direct PCR. The remaining portion of the lyophilized powder was rehydrated with MRScysteine broth, and then a loopful of rehydrated culture was streaked for isolation onto fresh MRS-cysteine agar and incubated under anaerobic $\left(5 \% \mathrm{H}_{2}, 10 \% \mathrm{CO}_{2}\right.$, and $85 \% \mathrm{~N}_{2}$ ) conditions at $37^{\circ} \mathrm{C}$ for $72 \mathrm{~h}$. After incubation, plates were evaluated for growth. White, shiny, convex colonies of similar size were considered pure culture. Stock culture was prepared for each isolate in either LLB or MRS ( $10 \%$ glycerol) and frozen at $-70^{\circ} \mathrm{C}$.

All strains were identified to the genus level by PCR using the Bifidobacterium genus-specific primer set $\operatorname{lm} 26$ and $\operatorname{lm} 3$ (Kaufmann et al., 1997). Briefly, fresh RT, ATCC, and DSMZ bifidobacteria stock cultures were cultured on solid media as described above. A portion of a single well-isolated colony was picked from the agar plate and transferred into PCR tubes, and cells were then lysed by microwaving PCR tubes containing the bifidobacterial cells for $7 \mathrm{~min}(750 \mathrm{~W})$ at high power (Bollet et al., 1991).

The PCR reaction mix contained $12.5 \mu \mathrm{L}$ Go Taq Green Master Mix (Promega Corp., Madison, WI), 1 $\mu \mathrm{L}$ of each primer pair $[1 \mu M$; Integrated DNA Technologies Inc. (IDT), Coralville, IA], lysed bifidobacterial cells, and nuclease-free water in a total volume of $25 \mu \mathrm{L}$. The negative control for the $\mathrm{PCR}$ reaction contained $25 \mu \mathrm{L}$ of the amplification mixture without any sample. The positive control for all PCR reactions was Bifidobacterium animalis ssp. lactis DSMZ $10140^{\mathrm{T}}$.

Polymerase chain reaction conditions for identification of the Bifidobacterium genus were described by Kaufmann et al. (1997). Polymerase chain reaction amplicons were separated by electrophoresis (80-100 V) in $1 \%$ agarose gels, stained with ethidium bromide, and visualized using an AlphaImager 3300 Gel Documentation System (Alpha Innotech Corp., San Leandro, CA).

Polymerase chain reaction was used to assess the species (subspecies) level identity of each of the RT bifidobacteria isolates using primers specific for Bifidobacterium adolescentis, B. animalis ssp. animalis, B. animalis ssp. lactis, Bifidobacterium longum ssp. longum, B. longum ssp. infantis, and Bifidobacterium bifidum, as described by Matsuki et al. (1999) and Ventura et al. (2001). Positive controls for species-specific PCR were the appropriate ATCC or DSMZ type strain for the species being examined (Table 1). Amplicons were detected as described previously. All RT bifidobacterial isolates were also evaluated using the B. animalis ssp. lactis-specific primer set as described by Ventura et al. (2001b). The positive control for this reaction was $B$. animalis ssp. lactis DSMZ $10140^{\mathrm{T}}$.

Lyophilized material collected from the commercial cultures was retrieved for direct PCR as described 
above. Cells were lysed using the microwave method and, following lysis, the PCR analyses as described above were conducted to determine if the species identified by the culture supplier could be detected. In addition, RT isolates were evaluated using the $B$. animalis ssp. lactis-specific primer set described by Ventura et al. (2001). Appropriate reference strains were included in each analysis.

All RT bifidobacteria isolates and B. animalis ssp. lactis DSMZ $10104^{\mathrm{T}}$ were streaked on LL agar and incubated at $37^{\circ} \mathrm{C}$ under anaerobic conditions for $72 \mathrm{~h}$ before characterization by pulsed-field gel electrophoresis (PFGE) using the method described by Briczinski and Roberts (2006). Briefly, cells were suspended in agarose plugs and lysed and then the DNA was digested using $X b a \mathrm{I}$ or SpeI (Promega Corp.). Electrophoresis was performed using the CHEF Mapper System (Bio-Rad Laboratories Inc., Hercules, CA). The experiment was performed in duplicate.

Deoxyribonucleic acid was isolated from RT bifidobacterial strains as described by Vincent et al. (1998). Amplification, band extraction, sequencing, and allelic profile constructs for the RT bifidobacterial isolates were performed as described by Briczinski et al. (2009).

The RT bifidobacteria, grown in anaerobic incubators on LLB and MRS-cysteine agar $\left(37^{\circ} \mathrm{C}, 72 \mathrm{~h}\right)$, formed white, convex, soft, shiny colonies with a well-defined round shape. The RT bifidobacterial strains grown in the anaerobic chamber on MRS-cysteine media formed larger, more uniform colonies than cells grown in the anaerobic incubator on LL.

Analysis of lyophilized RT bifidobacterial isolates revealed they were all members of the genus Bifidobacterium (data not shown). None of the RT bifidobacterial isolates showed a positive result for the species identified by the supplier when analyzed using the corresponding species-specific primers. Further analysis of the RT isolates by PCR using the $B$. animalis ssp. lactis species-specific primer pair revealed that all were isolates of B. animalis ssp. lactis (data not shown). Direct $\mathrm{PCR}$, performed using the lyophilized powder from the Ukrainian bifidobacteria cultures as template DNA, resulted in detection of only $B$. animalis ssp. lactis.

In an initial effort to differentiate the Ukrainian bifidobacteria, the isolates were evaluated using PFGE. No differences were observed between RT bifidobacteria isolates and B. animalis ssp. lactis DSMZ $10104^{\mathrm{T}}$ using $X b a \mathrm{I}$ and $S p e I$, with the exception of isolate RT 09 restricted with $X b a \mathrm{I}$, where one additional band was observed (data not shown).

Allelic profiles were created after sequencing of SNP and insertion-deletion polymorphism (INDEL) regions (Table 2). The phylogenetic tree created using these allelic profiles allowed assignment of the RT strains into specific groups. Single nucleotide polymorphism analysis revealed that the allelic profiles of 9 of the RT strains matched 3 distinct groups (Figure 1) described previously by Briczinski et al. (2009). The majority of RT strains (6) were clustered into a group that matched the commercial control strain B. animalis ssp. lactis BB-12. Two isolates (RT 02, RT 09) matched ATCC 27536, whereas RT 08 matched the previously characterized commercial strain RB 7239. The final isolate (RT 04) exhibited a unique SNP in Balat_0051 and was placed on a new branch (Figure 1).

Growth of the bifidobacterial isolates was better on MRS-cysteine media in the anaerobic chamber where these organisms formed more uniform and larger colonies than when grown on LLB in the anaerobic incubator. It appears that either the more strictly anaerobic conditions or composition of the growth medium influenced colony size. Culture maintenance and manipulations in the anaerobic chamber, along with growth on MRS-cysteine agar, resulted in better bifidobacterial growth. This was not unexpected, as bifidobacteria are sensitive to oxygen (de Vries and Stouthamer, 1969) and growth under oxidative stress differs among the bifidobacterial species (Shimamura et al., 1992). Meile et al. (1997) reported no growth of $B$. longum and $B$. animalis at elevated oxygen concentration, whereas $B$. animalis ssp. lactis tolerated oxygen. However, regardless of the incubation system used (anaerobic incubator or anaerobic chamber), only B. animalis ssp. lactis was recovered from the culture samples obtained from Ukraine.

Direct PCR was conducted using samples of the lyophilized culture as the source of template DNA to determine if the reason that only $B$. animalis ssp. lactis was recovered from commercial cultures was the inability to culture the target strains. Results obtained from this analysis confirmed that only B. animalis ssp. lactis was present in the samples. These data suggest that all 10 bifidobacterial isolates obtained from Ukraine contained high levels of $B$. animalis ssp. lactis and that, if the designated strains were present, the numbers were too small to detect using the conditions applied in this study. Based on these results, it appears that the typing methods used by the commercial supplier routinely resulted in assignment of the correct genus, but incorrect species.

No differences were detected between the RT bifidobacterial isolates and $B$. animalis ssp. lactis DSMZ $10104^{\mathrm{T}}$ digested with $\mathrm{XbaI}$ and $S p e \mathrm{I}$ with the exception of RT 09 restricted with $X b a I$. As previously reported, the monomorphic nature of the $B$. animalis ssp. lactis genome limits the utility of PFGE for differentiation of strains of this organism (Barrangou et al., 2009; Briczinski et al., 2009). 


\begin{tabular}{|c|c|c|c|c|c|c|c|c|c|c|c|c|}
\hline \multirow{2}{*}{$\begin{array}{l}\text { Genome } \\
\text { position in } \\
\text { DSMZ }^{1} 10140\end{array}$} & \multicolumn{4}{|c|}{ SNP in noncoding regions } & \multicolumn{6}{|c|}{ Nonsynonymous SNP in protein-coding regions } & \multicolumn{2}{|c|}{ INDEL } \\
\hline & 687000 & 959934 & 1456329 & 1636606 & 53321 & 53378 & 159526 & 993008 & 1260073 & 1260380 & 902893 & 1512304 \\
\hline DSMZ $10140^{2}$ & G & $\mathrm{G}$ & - & $\mathrm{A}$ & G & G & G & $\mathrm{T}$ & $\mathrm{C}$ & $\mathrm{T}$ & 1 & 1 \\
\hline BL-04 ${ }^{2,3}$ & A & $\mathrm{A}$ & $\mathrm{G}$ & G & $\mathrm{A}$ & $\mathrm{G}$ & - & $\mathrm{C}$ & G & $\mathrm{T}$ & 2 & 2 \\
\hline $\mathrm{RB} 4825^{4}$ & $\mathrm{~A}$ & $\mathrm{~A}$ & $\mathrm{G}$ & $\mathrm{G}$ & $\mathrm{A}$ & $\mathrm{G}$ & - & $\mathrm{C}$ & $\mathrm{G}$ & $\mathrm{T}$ & 2 & 2 \\
\hline RB 5251 & $\mathrm{~A}$ & $\mathrm{~A}$ & $\mathrm{G}$ & $\mathrm{G}$ & $\mathrm{A}$ & $\mathrm{G}$ & - & $\mathrm{C}$ & $\mathrm{G}$ & $\mathrm{T}$ & 2 & 2 \\
\hline HN $019^{2,3,5}$ & G & G & - & A & $\mathrm{A}$ & G & G & $\mathrm{T}$ & $\mathrm{C}$ & $\mathrm{T}$ & 1 & 1 \\
\hline $\mathrm{V9}^{2,5}$ & $\mathrm{G}$ & $\mathrm{G}$ & - & $\mathrm{G}$ & $\mathrm{A}$ & $\mathrm{G}$ & - & $\mathrm{T}$ & $\mathrm{C}$ & $\mathrm{T}$ & 2 & 1 \\
\hline $\mathrm{RB} 4753$ & G & G & - & G & A & G & - & $\mathrm{T}$ & $\mathrm{C}$ & $\mathrm{T}$ & 2 & 1 \\
\hline RB 1791 & $\mathrm{G}$ & $\mathrm{G}$ & - & $\mathrm{G}$ & $\mathrm{A}$ & $\mathrm{G}$ & - & $\mathrm{T}$ & $\mathrm{C}$ & $\mathrm{C}$ & 2 & 1 \\
\hline $\mathrm{BB} 12^{2,3,5}$ & G & G & - & G & $\mathrm{A}$ & G & - & $\mathrm{T}$ & $\mathrm{C}$ & $\mathrm{T}$ & 1 & 1 \\
\hline RT $01^{6}$ & G & G & - & G & $\mathrm{A}$ & G & - & $\mathrm{T}$ & $\mathrm{C}$ & $\mathrm{T}$ & 1 & 1 \\
\hline RT 03 & $\mathrm{G}$ & $\mathrm{G}$ & - & $\mathrm{G}$ & $\mathrm{A}$ & $\mathrm{G}$ & - & $\mathrm{T}$ & $\mathrm{C}$ & $\mathrm{T}$ & 1 & 1 \\
\hline RT 05 & G & $\mathrm{G}$ & - & $\mathrm{G}$ & $\mathrm{A}$ & $\mathrm{G}$ & - & $\mathrm{T}$ & $\mathrm{C}$ & $\mathrm{T}$ & 1 & 1 \\
\hline RT 06 & G & G & - & G & $\mathrm{A}$ & G & - & $\mathrm{T}$ & $\mathrm{C}$ & $\mathrm{T}$ & 1 & 1 \\
\hline RT 07 & G & $\mathrm{G}$ & - & G & A & $\mathrm{G}$ & - & $\mathrm{T}$ & $\mathrm{C}$ & $\mathrm{T}$ & 1 & 1 \\
\hline RT 10 & $\mathrm{G}$ & $\mathrm{G}$ & - & $\mathrm{G}$ & $\mathrm{A}$ & $\mathrm{G}$ & - & $\mathrm{T}$ & $\mathrm{C}$ & $\mathrm{T}$ & 1 & 1 \\
\hline RB 1573 & G & $\mathrm{G}$ & - & G & $\mathrm{A}$ & G & - & $\mathrm{T}$ & $\mathrm{C}$ & $\mathrm{T}$ & 1 & 1 \\
\hline RB 4052 & G & G & - & G & A & G & - & $\mathrm{T}$ & $\mathrm{C}$ & $\mathrm{T}$ & 1 & 1 \\
\hline RB 4536 & G & G & - & G & $\mathrm{A}$ & G & - & $\mathrm{T}$ & $\mathrm{C}$ & $\mathrm{T}$ & 1 & 1 \\
\hline RB 7339 & $\mathrm{G}$ & $\mathrm{G}$ & - & $\mathrm{G}$ & $\mathrm{A}$ & $\mathrm{G}$ & - & $\mathrm{T}$ & $\mathrm{C}$ & $\mathrm{T}$ & 1 & 1 \\
\hline RB 9321 & $\mathrm{G}$ & $\mathrm{G}$ & - & $\mathrm{G}$ & $\mathrm{A}$ & $\mathrm{G}$ & - & $\mathrm{T}$ & $\mathrm{C}$ & $\mathrm{T}$ & 1 & 1 \\
\hline $\mathrm{BI}-07^{3}$ & A & $\mathrm{A}$ & - & $\mathrm{G}$ & $\mathrm{A}$ & $\mathrm{G}$ & - & $\mathrm{C}$ & G & $\mathrm{T}$ & 1 & 2 \\
\hline RB 1281 & A & $\mathrm{A}$ & - & G & $\mathrm{A}$ & G & - & $\mathrm{C}$ & G & $\mathrm{T}$ & 1 & 2 \\
\hline RB 5733 & $\mathrm{~A}$ & $\mathrm{~A}$ & - & G & $\mathrm{A}$ & $\mathrm{G}$ & - & $\mathrm{C}$ & $\mathrm{G}$ & $\mathrm{T}$ & 1 & 2 \\
\hline RB 8613 & $\mathrm{~A}$ & $\mathrm{~A}$ & - & $\mathrm{G}$ & $\mathrm{A}$ & $\mathrm{G}$ & - & $\mathrm{C}$ & $\mathrm{G}$ & $\mathrm{T}$ & 1 & 2 \\
\hline RB 9632 & A & A & - & G & A & G & - & $\mathrm{C}$ & G & $\mathrm{T}$ & 1 & 2 \\
\hline ATCC 27536 & G & $\mathrm{A}$ & - & G & $\mathrm{A}$ & G & - & $\mathrm{T}$ & $\mathrm{C}$ & $\mathrm{T}$ & 1 & 1 \\
\hline RT 02 & G & $\mathrm{A}$ & - & $\mathrm{G}$ & $\mathrm{A}$ & $\mathrm{G}$ & - & $\mathrm{T}$ & $\mathrm{C}$ & $\mathrm{T}$ & 1 & 1 \\
\hline RT 09 & G & $\mathrm{A}$ & - & $\mathrm{G}$ & $\mathrm{A}$ & G & - & $\mathrm{T}$ & $\mathrm{C}$ & $\mathrm{T}$ & 1 & 1 \\
\hline RB 1280 & G & G & - & G & G & G & - & $\mathrm{T}$ & $\mathrm{C}$ & $\mathrm{T}$ & 1 & 1 \\
\hline RB 5851 & G & $\mathrm{A}$ & - & G & A & G & - & $\mathrm{T}$ & $\mathrm{C}$ & $\mathrm{T}$ & 1 & 1 \\
\hline RT 08 & G & G & - & G & $\mathrm{A}$ & G & - & $\mathrm{T}$ & $\mathrm{C}$ & $\mathrm{C}$ & 1 & 1 \\
\hline RB 7239 & $\mathrm{G}$ & $\mathrm{G}$ & - & $\mathrm{G}$ & $\mathrm{A}$ & $\mathrm{G}$ & - & $\mathrm{T}$ & $\mathrm{C}$ & $\mathrm{C}$ & 1 & 1 \\
\hline RB 5859 & G & G & $\mathrm{G}$ & G & A & G & - & $\mathrm{C}$ & $\mathrm{C}$ & $\mathrm{C}$ & 1 & 1 \\
\hline $\mathrm{BB}-02^{3}$ & $\mathrm{~A}$ & $\mathrm{~A}$ & $\mathrm{G}$ & G & $\mathrm{A}$ & G & - & $\mathrm{C}$ & $\mathrm{G}$ & $\mathrm{T}$ & 1 & 2 \\
\hline RB 3046 & A & $\mathrm{A}$ & G & $\mathrm{G}$ & A & $\mathrm{G}$ & - & $\mathrm{C}$ & $\mathrm{G}$ & $\mathrm{T}$ & 1 & 2 \\
\hline RB 5422 & A & A & G & G & $\mathrm{A}$ & G & - & $\mathrm{C}$ & G & $\mathrm{T}$ & 1 & 2 \\
\hline RT 04 & G & G & - & G & $\mathrm{A}$ & A & $\mathrm{G}$ & $\mathrm{T}$ & $\mathrm{C}$ & $\mathrm{T}$ & 1 & 1 \\
\hline RB 0171 & A & A & - & G & A & G & G & $\mathrm{C}$ & G & $\mathrm{T}$ & 1 & 2 \\
\hline $\mathrm{ADO}_{11}{ }^{2,5}$ & G & G & - & G & $\mathrm{A}$ & $\mathrm{G}$ & G & $\mathrm{T}$ & $\mathrm{C}$ & $\mathrm{T}$ & 2 & 1 \\
\hline Gene name & $\operatorname{Igr} 6$ & $\operatorname{Igr} 7$ & $\operatorname{Igr} 8$ & Igr9 & Balat_0051 & Balat_0051 & Balat_0141 & Balat_0864 & glcU & glcU & INDEL2 & INDEL3 \\
\hline
\end{tabular}

${ }^{1}$ DSMZ = Deutsche Sammlung von Microorganismen and Zellkulturen GmbH (German Collection of Microorganisms and Cell Cultures, Braunschweig, Germany)

${ }^{2}$ Boldface indicates a fully sequenced reference genome for B. animalis ssp. lactis.

${ }^{3}$ Common commercial strain of B. animalis ssp. lactis Bl-04 (Danisco USA Inc., Madison, WI), HN-019, BB-12 (Chr. Hansen A/S, Hørsholm, Denmark), BI-07 (Danisco USA Inc.), and BB-02 (Danisco USA Inc.).

${ }^{4} \mathrm{RB}$ represents a set of commercial strains of B. animalis ssp. lactis analyzed by Briczinski et al. (2009).

${ }^{5} \mathrm{SNP}$ profiles for HN-019, V9, and ADO11 were determined in silico.

${ }^{6} \mathrm{RT}$ represents a set of commercial B. animalis ssp. lactis isolates obtained from Ukraine and characterized in this study. 


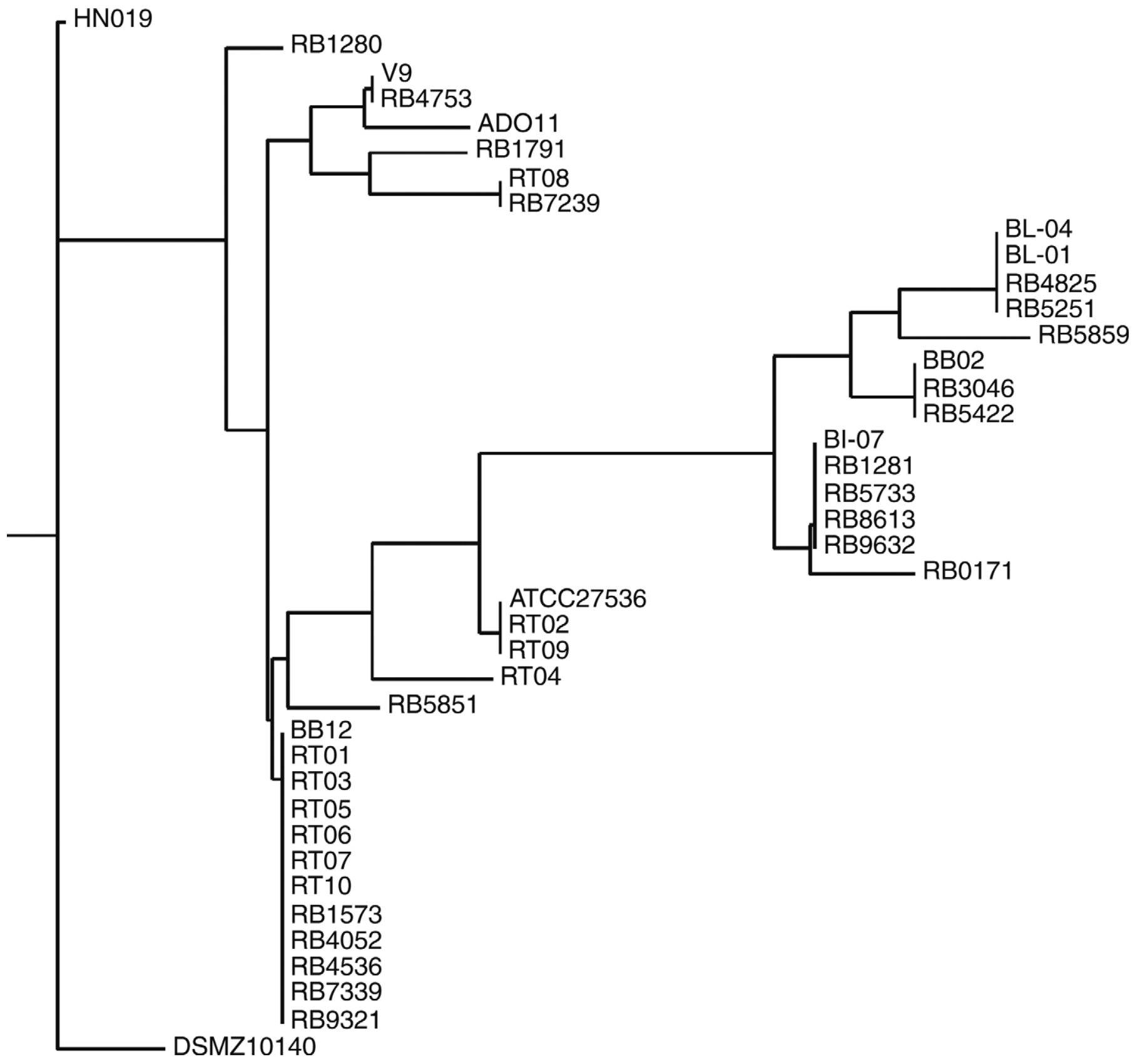

Figure 1. Cluster diagram placing the Ukrainian bifobacterial isolates, designated RT, into the scheme of bifidobacterial isolates in the scheme of Briczinski et al. (2009). Common commercial strains (HN019, Bl-04, BB-02, BI-07, ADO11, and BB-12) were included in the analysis for reference purposes.

Application of genome-wide SNP and INDEL analysis has recently been shown to be capable of differentiating isolates of $B$. animalis ssp. lactis (Briczinski et al., 2009). In the present study, SNP/INDEL analysis was able to separate RT strains into 4 distinct groups. Six strains had allelic profiles identical to the commonly used commercial strain BB-12. Single nucleotide polymorphism analysis of RT 02 and RT 09 revealed an allelic profile identical to that of ATCC 27536 (Table 2).
Strain RT 08 had an allelic profile identical to that of the previously characterized strain RB 7239. Strain RT 04 was found to have a unique profile and was placed in its own group. These results demonstrate the utility of SNP analysis for differentiation of strains of $B$. animalis ssp. lactis.

Knowing that bifidobacteria are anaerobic and that the sensitivity to oxygen differs dramatically, it is hypothesized that, if the initial determination of the 
identity of bifidobacterial strains obtained from commercial supplier from Ukraine was correct, the RT strains may have been exposed to oxygen during culturing, and were contaminated with and then overgrown by $B$. animalis ssp. lactis during culture production by the Ukrainian supplier. Alternatively, it is possible the methods initially employed by the supplier to identify these organisms did not allow for accurate species-level identification.

Accurate identification to the species and strain level is a crucial control element when producing fermented dairy products containing probiotic bacteria and, in fact, the probiotic effects of bifidobacteria are considered to be strain-specific (FAO/WHO, 2002). In previous work, Huys et al. (2006) reported that $28 \%$ of commercial strains were misidentified at the genus or species level. Temmerman et al. (2003) noted mislabeling of strains contained in some preparations and also commented on the use of old or inappropriate nomenclature. The need for policies regulating microbiological quality and labeling of probiotic products and pharmaceutical preparations has been suggested by various authors (Sanders and Huis in't Veld, 1999; Szajewska et al., 2004; Harish and Varghese, 2006) and is highlighted and reconfirmed by this study.

Results obtained in this study revealed all 10 of the Ukrainian bifidobacterial cultures were correctly identified by the culture supplier at the genus level, but were misidentified at the species/subspecies level. All of the isolates evaluated were determined to be strains of B. animalis ssp. lactis. As expected, PFGE exhibited limited discriminatory power when applied to differentiation of this subspecies (Barrangou et al., 2009; Briczinski et al., 2009). Whole-genome SNP and INDEL analysis was able to separate the Ukrainian isolates into 4 separate groups and was found to be more discriminative than PFGE. Perhaps not surprisingly, 6 of the 10 Ukrainian strains evaluated were assigned to the group containing the well-known commercial strain B. animalis ssp. lactis BB-12 and 2 were assigned to the group containing the culture collection strain ATCC 27536. These results highlight the importance of effective strain identification and differentiation and clearly suggest that attention be given to ensure the identity of the bifidobacteria used in probiotic-containing dairy products to ensure continued consumer confidence in these products. It is recommended that manufacturers who are adding specific probiotics to products require adequate documentation of strain identity from the supplier and consider implementing procedures to verify the species or, where possible, the strain being added to the product. In addition, the results demonstrate the utility of SNP/INDEL-based allelic typing in $B$. animalis ssp. lactis strain differentiation and further point to the limited genetic variability of $B$. animalis ssp. lactis strains and the worldwide distribution of a small number of commercial strains.

\section{REFERENCES}

Barrangou, R., E. Briczinski, L. Traeger, J. Loquasto, M. Richards, P. Horvath, A. Coute-Monvoisin, G. Leyer, S. Rendulic, J. Steele, J. Broadbent, T. Oberg, E. Dudley, S. Schuster, D. Romero, and R. Roberts. 2009. Comparison of the complete genome sequences of Bifidobacterium animalis ssp. lactis DSM 10140 and Bl-04. J. Bacteriol. 191:4144-4151.

Bollet, C., M. J. Gevaudan, X. de Lamballerie, C. Zandotti, and P. de Micco. 1991. A simple method for the isolation of chromosomal DNA from Gram-positive or acid-fast bacteria. Nucleic Acids Res. $19: 1955$.

Bondarenko, A., B. Bondarenko, and B. Bondarenko. 1998. Puti sovershenstvovanija etiopatogeneticheskoy terapii disbakteriozov. Zhurnal Mikrobiologii 5:96-101.

Briczinski, E. P., J. R. Loquasto, R. Barrangou, E. G. Dudley, A. M. Roberts, and R. F. Roberts. 2009. Strain-specific genoptyping of Bifidobacterium animalis ssp. lactis using SNPs and INDELs. Appl. Environ. Microbiol. 75:7501-7508.

Briczinski, E. P., and R. F. Roberts. 2006. Technical note: A rapid pulsed-field gel electrophoresis method for analysis of bifidobacteria. J. Dairy Sci. 89:2424-2427.

de Vries, W., and A. H. Stouthamer. 1969. Factors determining the degree of anaerobiosis of Bifidobacterium strains. Arch. Mikrobiol. 65:275-287.

FAO/WHO. 2002. Guidelines for the Evaluation of Probiotics in Foods. WHO, Geneva, Switzerland, London, Ontario, Canada.

Grigorov, Y., T. Semes'ko, L. Zhivaga, and V. Chagarovskiy. 2002. Mediko-biologicheskie issledovaniya kislomolochnykh productov "Bio-kefir" i "Bioyogurt". Molochna promislovist' 2:44-46.

Harish, K., and T. Varghese. 2006. Probiotics in humans: Evidence based review. Calicut Med. J. 4:e3.

Huys, G., M. Vancanneyt, K. D'Haene, V. Vankerckhoven, H. Goossens, and J. Swings. 2006. Accuracy of species identity of commercial bacterial cultures intended for probiotic or nutritional use. Res. Microbiol. 157:803-810.

Kaufmann, P., A. Pfefferkorn, M. Teuber, and L. Meile. 1997. Identification and quantification of Bifidobacterium species isolated from food with genus-specific 16S rRNA-targeted probes by colony hybridization and PCR. Appl. Environ. Microbiol. 63:1268-1273.

Kovalenko, N. 2002. Razrabotka productov funktsional'nogo pitaniya na osnove molochkislyckh bakteriy i ikh prakticheskoe ispol'zovanie. Molochna promislovist' 1:22.

Kvasnikov, E. 1992. Mesto i znachenie molochnokislykh bakteriy v biosfere-Eskiz. Mikrobiol. Zh. 54:3-10.

Lapierre, L., P. Undeland, and L. J. Cox. 1992. Lithium chloridesodium propionate agar for the enumeration of bifidobacteria in fermented dairy products. J. Dairy Sci. 75:1192-1196.

Matsuki, T., K. Watanabe, R. Tanaka, M. Fukuda, and H. Oyaizu. 1999. Distribution of bifidobacterial species in human intestinal microflora examined with 16S rRNA-gene-targeted species-specific primers. Appl. Environ. Microbiol. 65:4506-4512.

Meile, L., W. Ludwig, U. Rueger, C. Gut, P. Kaufmann, G. Dasen, S. Wenger, and M. Teuber. 1997. Bifidobacterium lactis sp. nov., a moderately oxygen tolerant species isolated from fermented milk. Syst. Appl. Microbiol. 20:57-64.

Ott, B., and V. Chagarovskiy. 2002. Klinicheskay aprobatsia kislomolochnikh productov "Bio-kefir" and "Bio-yogurt". Molochna promislovist' 3:36-38.

Sanders, M. E., and J. Huis in't Veld. 1999. Bringing a probioticcontaining functional food to the market: Microbiological, product, regulatory and labeling issues. Antonie van Leeuwenhoek $76: 293-315$.

Shimamura, S., E. Abe, N. Ishibashi, H. Mikayawa, T. Yeashima, T. Araya, and M. Tomita. 1992. Relationship between oxygen sensitivity and oxygen metabolism of Bifidobacterium species. J. Dairy Sci. 75:3296-3306. 
Szajewska, H., A. Fordymacka, J. Bardowski, R. Górecki, J. Mrukowicz, and A. Banaszkiewicz. 2004. Microbiological and genetic analysis of probiotic products licensed for medicinal purposes. Med. Sci. Monit. 10:BR346-BR350.

Temmerman, R., I. Scheirlinck, G. Huys, and J. Swings. 2003. Cultureindependent analysis of probiotic products by denaturing gradient gel electrophoresis. Appl. Environ. Microbiol. 69:220-226.
Ventura, M., R. Reniero, and R. Zink. 2001. Specific identification and targeted characterization of Bifidobacterium lactis from different environmental isolates by a combined multiplex-PCR approach. Appl. Environ. Microbiol. 67:2760-2765.

Vincent, D., D. Roy, F. Mondou, and C. Dery. 1998. Characterization of bifidobacteria by random DNA amplification. Int. J. Food Microbiol. 43:185-193. 